\title{
1 Mechanisms of orthostatic intolerance during heat stress
}

2

3 Zachary J. Schlader ${ }^{1}$, Thad E. Wilson ${ }^{2}$, Craig G. Crandall ${ }^{3}$

4

$5{ }^{1}$ Department of Exercise and Nutrition Sciences, University at Buffalo, Buffalo, NY

$6{ }^{2}$ Marian University College of Osteopathic Medicine, Indianapolis, IN

$7{ }^{3}$ Institute for Exercise and Environmental Medicine, Texas Health Presbyterian Hospital

8 Dallas and University of Texas Southwestern Medical Center, Dallas, TX

9

10 Corresponding Author:

11 Zachary J. Schlader

12 Department of Exercise and Nutrition Sciences

13 University at Buffalo

14 204A Kimball Tower

15 Buffalo, NY 14214

16 Phone: 716-829-6794

17 Fax: 716-829-2428

18 Email: zjschlad@buffalo.edu

19

20 Word count: 6253

21 Abstract word count: 198

22 Number of figures: 5

23 Number of references: 177 


\section{Abstract}

25 Heat stress profoundly and unanimously reduces orthostatic tolerance. This review aims

26 to provide an overview of the numerous and multifactorial mechanisms by which this occurs

27 in humans. Potential causal factors include changes in arterial and venous vascular 28 resistance and blood distribution, and the modulation of cardiac output, all of which 29 contribute to the inability to maintain cerebral perfusion during heat and orthostatic stress.

30 A number of countermeasures have been established to improve orthostatic tolerance 31 during heat stress, which alleviate heat stress induced central hypovolemia (e.g., volume 32 expansion) and/or increase peripheral vascular resistance (e.g., skin cooling). 33 Unfortunately, these countermeasures can often be cumbersome to use with populations 34 prone to syncopal episodes. Identifying the mechanisms of inter-individual differences in 35 orthostatic intolerance during heat stress has proven elusive, but could provide greater 36 insights into the development of novel and personalized countermeasures for maintaining 37 or improving orthostatic tolerance during heat stress. This development will be especially 38 impactful in occuational settings and clinical situations that present with orthostatic intolerance and/or central hypovolemia. Such investigations should be considered of vital 40 importance given the impending increased incidence of heat events, and associated 41 cardiovascular challenges that are predicted to occur with the ensuing changes in climate. 42

43 Keywords: Orthostasis, cardiovascular control, sympathetic nerve activity, hyperthermia, 44 cutaneous blood flow 


\section{Introduction}

Global temperatures are rising (Easterling et al., 2000b; Meehl et al., 2007) and weather is predicted to become more variable (Easterling et al., 2000a; Easterling et al., 2000b; Folland et al., 2006; Ratcliffe et al., 2006). This greater weather variability is defined by an increased frequency, intensity, and duration of heat events (Easterling et al., 2000a; Easterling et al., 2000b; Folland et al., 2006; Meehl et al., 2004; Ratcliffe et al., 2006). Cardiovascular health is particularly susceptible to environmental heat, such that a large proportion of the morbidity and mortality during heat events is from cardiovascular causes (Anderson et al., 2009; Danet et al., 1999; Huynen et al., 2001; Kaiser et al., 2007; Kenney et al., 2014a; Knowlton et al., 2009; Vandentorren et al., 2006). Importantly, 2014 was the hottest year on record (Organization, 2015), and hence environmental heat is not only a problem of the future. It is clear, therefore, that currently, and to a larger extent in the forthcoming years, environmental heat poses a significant challenge to the cardiovascular system and health.

When the rate of body heat loss is exceeded by the rate of environmental or internal heat gain, heat stress ensues, which is characterized by elevations in both skin and internal temperatures. Notably, elevations in internal temperature of as little as $\sim 3^{\circ} \mathrm{C}$ above 'normothermia' (i.e., $\sim 37^{\circ} \mathrm{C}$ ) severely strain physiological systems and can even lead to death (Bouchama et al., 2002). Prevailing evidence suggests that heat loss is primarly controlled by skin sympathetic nerves innervating skin blood vessels and eccrine sweat glands (Hagbarth et al., 1972; Low et al., 2011; Normell et al., 1974), although the precise mechanisms remain unclear (Kellogg, 2006). Heat stress induces cutaneous vasodilation, which allows for increases in skin blood flow of 5-7 L/min (Rowell, 1974), reducing systemic vascular resistance (Rowell et al., 1969). Heat stress also induces sweating, which can result in a sweat rate of upwards to $3 \mathrm{~L} / \mathrm{hr}$ (Armstrong et al., 1986), reducing circulating fluid volume (Mack et al., 2011). To regulate blood pressure, cardiac output must increase proportionately (Rowell et al., 1969). This is made possible through elevations in heart rate (Rowell, 1974) and cardiac contractility (Brothers et al., 2009a; Bundgaard-Nielsen et al., 2010; Lucas et al., 2015; Nelson et al., 2011a; Stöhr et al., 2011; Wilson et al., 2009a), as well as a redistribution of blood flow and volume away from non-cutaneous regions (e.g., splanchnic and renal vascular beds) (Crandall et al., 2008; Minson et al., 1998; Rowell et al., 1968; Rowell et al., 1971b). These responses are also largely mediated via the sympathetic nervous system (Rowell, 1990), as evidenced by increases in plasma 
78 catecholamine concentrations (Gagnon et al., 2015b; Niimi et al., 1997) and muscle 79 sympathetic nerve activity (Cui et al., 2010; Cui et al., 2002; Gagnon et al., 2015b; Low et

80 al., 2011; Niimi et al., 1997), which increase in proportion to the magnitude of heat stress.

81 During most instances, these responses are sufficiently robust to ensure reductions in 82 blood pressure are minimal (only on the order of $5-10 \mathrm{mmHg}$ ) (Crandall et al., 2014; 83 Rowell, 1974). That said, when heat stress is overlayed with an additional challenge to 84 blood pressure, such as orthostasis, blood pressure regulation can become compromised.

85 The purpose of this review is to provide a concise overview of the physiological 86 mechanisms by which heat stress challenges orthostatic tolerance. We will also review the 87 current evidence regarding inter-individual differences in orthostatic tolerance during heat 88 stress, as well as introduce proven and potential countermeasures that may be used to 89 promote orthostatic tolerance during heat stress. In the context of this review, 'heat stress' refers to the whole-body, passive (i.e., resting) state. Notably, this does not infer that passive heat stress data cannot be applied to the active (i.e., exercising) state. For instance, the orthostatic responses to passive and active heat stress are virtually indistiguishable when skin temperatures are similar (Pearson et al., 2014). During passive heat stress skin temperatures will be profoundly elevated $\left(37-40^{\circ} \mathrm{C}\right)$. The magnitude of the increase in internal body temperature will vary between the studies discussed, although it will usually be between $0.7-1.5^{\circ} \mathrm{C}$. In all instances, internal body temperature has been measured in the intestines (e.g., via ingestible temperature capsule), rectum, esophagous, mouth, or pulmonary artery. Because of the loss of body water due to sweating, heat stress and dehydration are intimately linked. However, this review will focus primarily on heat stress, although it should be noted that dehydration is an independent modulator of orthostatic tolerance, and has been identified to be an additive factor with heat stress in reducing orthostatic tolerance (Lucas et al., 2013a; Schlader et al., 2015).

\section{Heat stress impairs orthostatic tolerance}

Orthostasis results in central hypovolemia, which occurs as a result of blood pooling in the legs due to gravity. To maintain blood pressure during orthostasis, a challenge that reduces ventricular filling and thus stroke volume, a number of cardiovascular adjustments,

108 largely mediated by baroreflexes and the sympathetic nervous system, must transpire to 109 maintain cardiac output (Convertino, 2014; Esler, 2010; Fu et al., 2014; Mano et al., 2003). 110 Such adjustments include elevations in heart rate, cardiac contractility, and vascular 
111 resistance. If these adjustments are insufficient or if the required adjustments exceed the 112 capacity to modulate these variables, cardiovascular decompensation and rapid reductions 113 in blood pressure occur. If this compromises cerebral perfusion, then syncope ensues if the 114 central hypovolemic stimulus is not removed. The ability to withstand a given central 115 hypovolemic insult is experimentally referred to as orthostatic tolerance even if there is no 116 gravity or postural challenge. This can be safely evaluated in humans by inducing central 117 hypovolemia with perturbations such as lower body negative pressure (LBNP) to the point 118 of pre-syncope. Pre-syncope is identified by the onset of syncopal signs and symptoms, 119 which include feeling faint, sustained nausea, rapid and progressive decreases in blood 120 pressure resulting in sustained systolic blood pressure being $<80 \mathrm{mmHg}$ and/or relative 121 bradycardia accompanied by a narrowing of pulse pressure. Experimentally, when pre122 syncope occurs, the central hypovolemic stimulus is immediately terminated and the 123 syncopal signs and symptoms disappear.

124 Heat stress profoundly and unanimously reduces orthostatic tolerance. This is portrayed 125 in Figure 1, which presents data from the database out of the Thermal and Vascular 126 Physiology Laboratory in Dallas, TX, USA, which contains a total of 184 observations in 127 which subjects underwent progressive central hypovolemia to pre-syncope via LBNP. 128 Subjects were either heat stressed $\left(1.4 \pm 0.2^{\circ} \mathrm{C}\right.$ increase in internal temperature) or 129 normothermic (control condition). Orthostatic tolerance was quantified via the cumulative 130 stress index, which is calculated by summing the product of the level of LBNP and the time 131 at each level of LBNP across the trial until pre-syncope (i.e., $20 \mathrm{mmHg} \times 3 \mathrm{~min}+30 \mathrm{mmHg}$ 132 x $3 \mathrm{~min}$, etc.) (Levine et al., 1994). Figure 1 demonstrates a left-ward shift in the Kaplan133 Meier survival curve, indicating that orthostatic tolerance during progressive LBNP is 134 impaired during heat stress (Figure 1).

135 Heat stress induced orthostatic intolerance is not a recent finding. Observations dating to 1361949 noted reductions in orthostatic tolerance during head-up tilt following immersion in a 137 hot $\left(40^{\circ} \mathrm{C}\right)$ bath (Horvath et al., 1949). Studies from then through to the present have 138 confirmed these findings during head-up tilt (Lind et al., 1968; Shvartz et al., 1970; Wilson 139 et al., 2002b; Yamazaki et al., 2000), while others have consistently demonstrated that 140 orthostatic tolerance is reduced while heat stressed during other central hypovolemic 141 stimuli such as LBNP (Keller et al., 2009; Pearson et al., 2013; Schlader et al., 2014a; 142 Schlader et al., 2014b; Wilson et al., 2006), centrifugation (Nunneley et al., 1979), and 143 linear acceleration (Allan et al., 1972). Given the integrative nature of the cardiovascular 
144 responses required to maintain blood pressure during orthostasis, the mechanisms 145 underlying heat stress induced impariments in orthostatic tolerance are multifactorial. 146 These potential mechanisms, which include the control of cardiac output, vascular 147 resistance, venous responses, and the cerebral circulation, are discussed in the following 148 sections.

\section{Mechanisms of orthostatic intolerance during heat stress}

151 Control of cardiac output

152 During orthostasis, the heart must deliver blood to generate sufficient blood pressure to 153 perfuse the brain and stave off syncope. While this appears to be a simple engineering 154 task, the physiological responses to heat stress place the heart at some distinct 155 disadvantages to appropriately respond to the additional stress of orthostasis. As a result, 156 producing the necessary cardiac output to compensate for both heat and orthostatic stress 157 is physiologically challenging. We would like to emphasize using the term necessary to 158 describe the cardiac output requirements under combined heat and orthostatic stress, since 159 the cardiac output required under these combined stressors may not appear aberrantly low 160 to the clinician, but is in fact inadequate for the conditions. Highlighting this concept, 161 cardiac output at pre-syncope during heat stress can be much higher than normothermic 162 baseline values (Ganio et al., 2012).

163 Inadequate cardiac output is a key mechanism by which heat stress alters orthostatic 164 tolerance. For instance, volume expansion increases cardiac output during heat stress and 165 attenuates reductions in cardiac output during central hypovolemia (Bundgaard-Nielsen et 166 al., 2010), and under such circumstances, volume expansion during heat stress restores 167 orthostatic tolerance to normothermic levels (Keller et al., 2009) (Figure 2). Notably, cardiac 168 output can be modulated via alterations in stroke volume and/or heart rate.

169 Cardiac preload modulates stroke volume and likely affects cardiac output responses 170 during combined heat and orthostatic stress. Due to reductions in systemic vascular 171 resistance and associated increases in blood volume in the cutaneous vasculature, heat 172 stress, alone, decreases central blood volume (Crandall et al., 2012; Crandall et al., 2008), 173 which reduces cardiac preload (Wilson et al., 2009a) and potentially compromises stroke 174 volume. The relationship between cardiac preload and stroke volume is not linear, as 175 reductions in cardiac preload affect stroke volume based, in part, on the magnitude of left 176 ventricular stretch (i.e., the Frank-Starling effect). Isolated heart studies indicate that the 
177 shape of the Frank-Starling curve is not altered within physiological heat stress ranges 178 (Klabunde et al., 2013). Rather, heat stress shifts the operating point of the Frank-Starling 179 curve closer to the steep portion of the curve (Bundgaard-Nielsen et al., 2010; Wilson et al., 180 2009b). With this arrangement, further decreases in pulmonary capillary wedge pressure 181 (i.e., left ventricular stretch / preload), such as would occur during orthostasis (Levine, 182 1993), cause more profound decreases in stroke volume when heat stressed compared to 183 when normothermic. Ultimately, this may compromise cardiac output to the point where 184 blood pressure is severely compromised.

185 Increases in cardiac contractility could help maintain stroke volume during heat stress 186 independent of Frank-Starling effects. This would help promote the maintenance of stroke 187 volume and thus, cardiac output, during combined heat and orthostatic stress, in spite of 188 reductions in cardiac preload. In line with this contention, heat stress increases cardiac 189 contractility (Bundgaard-Nielsen et al., 2010; Crandall et al., 2008; Nelson et al., 2010; 190 Stöhr et al., 2011; Wilson et al., 2009a). Importantly, during combined heat and orthostatic 191 stress cardiac contractility is greater than when compared to heat stress alone (Nelson et 192 al., 2011a). Isolated heart studies indicate that within physiological heat stress ranges, 193 inotropic agonists are not more effective at higher temperatures (Klabunde et al., 2013), 194 suggesting that heat stress does not affect cardiac beta-adrenergic receptor transduction or 195 contractile mechanisms. Thus, the increase in contractility with heat stress, with or without 196 orthostasis, likely occurs via increases in cardiac sympathetic nerve activity, and is perhaps 197 contributed to by cardiac parasympathetic withdrawal (Vandecasteele et al., 1999). This 198 conclusion was recently confirmed in spinal cord injured individuals with limited/absent 199 sympathetic cardiac innervation (Shibasaki et al., 2015). Notably, the extent to which 200 increases in cardiac contractility help to maintain orthostatic tolerance during heat stress 201 remains to be determined.

202 Finally, from a mechanical pump viewpoint, instead of attempting to maintain pump 203 filling (cardiac preload) or pumping harder (cardiac contractility), the pump could simply 204 cycle more often (i.e., increase heart rate) to increase or maintain (cardiac) output. As 205 described above, heart rate increases during heat stress largely via sympathetic 206 enhancement, but also via parasympathetic withdrawal (Gorman et al., 1984; Jose et al., 207 1970). During orthostasis, heart rate also increases due primarily to baroreceptor 208 unloading, which occurs in response to drops in blood pressure (Convertino, 2014). During 209 combined heat and orthostatic stress, heart rate increases as blood pressure is reduced, 
210 resulting in greater peak heart rates during these combined stressors relative to orthostasis

211 in the absence of heat stress (Schlader et al., 2014a). However, the magnitude of the 212 increase in heart rate from pre- orthostatic stress is attenuated during heat stress 213 compared to normothermic conditions, which is likely due to higher heart rates while heat 214 stressed prior to orthostasis (Figure 3). These data suggest a sub-additive effect of heat 215 and orthostatic stress on heart rate, wherein the increase in heart rate during orthostasis is 216 attenuated during heat stress. It is notable, that the heart rates achieved during combined 217 heat and orthostatic stress were well below maximal levels for most subjects (averaging $218 \sim 130 \mathrm{bpm})$. The reason for this apparent blunted heart rate response remains unknown.

219 Importantly however, such an arrangement may be advantageous given that limiting 220 increases in heart rate may allow appropriate time for cardiac filling, particularly given 221 reduced ventricular filling pressures, which could otherwise become comprised if heart rate 222 were to approach maximal levels.

223 The primary feedback mechanisms for cardiac pump cycle frequency (heart rate) and 224 strength (contractility) during orthostasis are the baroreflexes. The effect of heat stress on 225 baroreflex function in humans has been extensively reviewed and readers are referred to 226 several excellent reviews on the topic (Crandall, 2008; Crandall et al., 2003; Crandall et al., 227 2010a; Crandall et al., 2014; Gonzalez-Alonso et al., 2008). In brief, the collective evidence 228 generally indicates that heat stress does not impair baroreflex control of the heart, although 229 there are exceptions. For example, heat stress does not change the maximum gain of the 230 carotid-to-cardiac baroreceptor response despite heart rate being elevated via heat stress 231 (Crandall, 2000; Yamazaki et al., 2000). However, integrated (multiple high and low 232 baroreceptor populations) baroreceptor-to-cardiac responses, using procedures such as a 233 Valsalva maneuver, appear to be impaired with heat stress (Davis et al., 2010; Yamazaki et 234 al., 2003). These results are contradictory and are likely a function of the various tests used 235 to examine aspects of the cardiac-baroreflex arcs (Crandall, 2008).

\section{Control of vascular resistance}

238 During orthostasis, vascular resistance must also increase to preserve blood pressure. 239 From an engineering perspective, this task could be more challenging than the control of 240 the heart (pump) since there are competing controls in the vasculature (tubes) during heat 241 stress - i.e., blood pressure regulation vs. heat dissipation (Kenney et al., 2014b). For 242 example, increases in systemic vascular resistance (or reductions in systemic vascular 
243 conductance) are minimal during combined heat and orthostatic stress despite profound 244 reductions in blood pressure (Ganio et al., 2012) (Figure 4). Thus, another mechanism by 245 which heat stress may impair orthostatic tolerance is via altered control of vascular 246 resistance. There are three potential explanations for these alterations: 1) heat stress 247 attenuates increases in cutaneous vascular resistance during orthostasis when cutaneous 248 beds are vasodilated due to heat stress (i.e., a sympatholytic-type effect); 2) non-cutaneous 249 vascular beds that are already experiencing a degree of heat stress induced sympathetic 250 vasoconstriction may not be capable of further vasoconstriction during a subsequent 251 orthostatic challenge; and/or 3) baroreflexes governing vascular control during orthostatic 252 stress may be altered by heat stress.

253 Crandall et al. (2010b) examined the cutaneous vascular responses to combined heat 254 and orthostatic stress and identified that cutaneous vascular resistance increased only a 255 minor extent leading up to pre-syncope. Given the large reserve of blood contained within 256 the cutaneous vasculature during heat stress (Rowell, 1974), these data suggest that 257 insufficient cutaneous vasoconstriction is likely a major contributor to impaired orthostatic 258 tolerance during heat stress. There are three potential reasons for this lack of 259 responsiveness. First, the cutaneous vasculature during heat stress is not as responsive to 260 a given quanta of sympathetic neurotransmitter (Wilson et al., 2002a), which is likely due to 261 nitric oxide mechanisms (Durand et al., 2005; Hodges et al., 2007; Low et al., 2007; 262 Shibasaki et al., 2007; Shibasaki et al., 2008). Second, there may be less withdrawal of 263 sympathetic vasodilator activity and/or less of an increase in sympathetic vasoconstrictor 264 activity to the skin during orthostasis (Cui et al., 2004b; Shibasaki et al., 2006; Wilson et al., 265 2001; Wilson et al., 2005). And third, heat stress impairs venous-arteriolar interactions (see 266 Veno-Arteriolar Response section below).

267 Both heat and orthostatic stress increase sympathetic vasoconstrictor outflow to the 268 muscle, splanchnic, and renal vasculatures. Thus, it is possible that when stresses are 269 combined, it may be difficult to further increase neural outflow and/or further vasoconstrict 270 to that neural signal. Minson et al. (1999) investigated this hypothesis and identified 271 comparable increase in both splanchnic and renal vascular resistance during orthostasis 272 between heat stress and normothermic conditions. Notably however, the level of heating 273 was relatively low (internal temperature increased $\sim 0.5^{\circ} \mathrm{C}$ ). These data indicate that both 274 splanchnic and renal vasoconstrictor responses to orthostasis may not be impeded during 275 heat stress. Furthermore, muscle blood flow is either unchanged (Heinonen et al., 2011) or 
276 modestly increased (Pearson et al., 2011) during heat stress, while muscle $\alpha$-adrenergic 277 vasoconstrictor responsiveness is not attenuated by local muscle heating (Keller et al., 278 2010). Such findings highlight a potentially paradoxical disconnect between sympathetic 279 nerve activity and vasoconstriction in the muscle vasculature. However, it may be that 280 sympathetic vasoconstrictor neural activity to the muscle is effectively putting a 'brake' on 281 heat stress induced reductions in vascular resistance that would otherwise compromise 282 blood pressure. Given such an arrangement, it may be that the extent by which increases 283 in muscle vascular resistance can be sympathetically elevated contributes to orthostatic 284 tolerance during heat stress. In support of this, Cui et al. (2011) identified that subjects with 285 the greatest increase in muscle sympathetic nerve activity during orthostasis under heat 286 stress had better orthostatic tolerance (Figure 5). Thus, an augmented sympathetic 287 response to the muscle may be a strategy to compensate, in part, for other vascular beds 288 that appear to be less influence by orthostasis and subsequent hypotension (e.g., the 289 cutaneous vasculature).

290 Similar to the aforementioned control of the heart, the manner in which vascular 291 resistance is modulated during orthostasis is largely via baroreflex mechanisms. Thus, any 292 heat stress induced alterations in vascular resistance during orthostasis could be 293 contributed to, or driven by, alterations in baroreflex control of the vasculature. Notably 294 however, baroreflex control of vascular resistance data are somewhat conflicting. For 295 instance, heat stress inhibits the carotid-to-vascular baroreflex (Crandall, 2000), suggesting 296 a greater potential for reductions in blood pressure during orthostasis when heat stressed. 297 That said, the sensitivity of baroreflex modulation of muscle sympathetic nerve activity 298 either is not altered (Cui et al., 2002) or is, in fact, improved (Keller et al., 2006) during heat 299 stress. Interestingly, both electrical stimulation of the carotid sinus nerve (Wallin et al., 300 1975) and unloading of the cardiopulmonary and carotid baroreceptors during both 301 normothermia and heat stress (Crandall et al., 1996) has no effect on the cutaneous 302 circulation. This highlights a potential baroreceptor mediated mechanism by which 303 cutaneous vascular resistance is largely unaffected by orthostasis when heat stressed 304 (Crandall et al., 2010b). Importantly, during normothermia, orthostasis increases the 305 sensitivity of the baroreflex to modulate vascular resistance (Fu et al., 2006; Schwartz et 306 al., 2012), and this appears to be maintained, or even accentuated, during heat stress (Cui 307 et al., 2004a). Thus, despite that baroreflex modulation appears to have minimal influence 
308 on the cutaneous vasculature, baroreflex modulation of the muscle vascular beds (e.g., MSNA responses) may be improved during combined heat and orthostatic stress.

Venous responses

As a consequence of heat stress induced decreases in cutaneous vascular resistance, cutaneous venous volume must also increase. The mechanisms by which this occurs are likely two fold. The first is associated with the Krogh model that describes changes in blood volume in the compliant venous bed associated with changes in vascular resistance in the upstream arteriolar bed (Krogh, 1912; Rowell, 1983). Specifically, as vascular resistance in

317 the cutaneous arterioles is reduced with heat stress, the pressure in the downstream capillary and venous bed is elevated. Due to the highly compliant nature of the venous bed, this elevation in cutaneous venous pressure results in a large increase in venous volume, which, in turn, reduces the transit time for the blood to pass through the cutaneous vasculature, facilitating the transfer of heat from the skin to the environment (Rowell, 1983; Rowell, 1986b). Conversely, during conditions of increased cutaneous vascular resistance

323 (i.e., skin cooling), the pressure in the cutaneous venous system is reduced and blood is 324 displaced from the cutaneous bed centrally. Importantly, therefore, based upon this Krogh model the lack of increases in cutaneous vascular resistance during orthostasis when heat stressed likely contributes to the lack of mobilization of blood out of the expanded cutaneous venous compartment into the central vasculature, which would otherwise serve to protect against orthostatic hypotension.

The second potential mechanism leading to increased cutaneous venous volume during heat stress is related to the direct and indirect effects of heat on venous tone. Although not consistently observed, it is generally accepted that high skin temperatures increase the 332 compliant nature of the cutaneous venous bed and attenuates venoconstriction 333 (sympatholytic effect), resulting in a greater capacitance at a given pressure (Greenfield et 334 al., 1956; Henry et al., 1949; Rowell, 1986a; Rowell et al., 1971a; Vanhoutte et al., 1970; 335 Webb-Peploe, 1969; Webb-Peploe et al., 1968a; Webb-Peploe et al., 1968b; Zitnik et al., 336 1971). This likely contributes to the greater reductions in central blood volume during 337 orthostasis while heat stressed (Crandall et al., 2008). Consistent with this mechanism, 338 Henry and Gauer (1950) showed a more rapid increase in foot venous pressure during orthostasis when the limb was heated relative when it was normothermic. Furthermore, 340 when that limb was cooled the increase in foot venous pressure was attenuated by $\sim 25 \%$ 
341 during orthostasis. These findings were later corroborated by those showing more rapid 342 increases in calf volume during orthostasis while heat stressed relative to when 343 normothermic (Yamazaki et al., 2002).

\section{Veno-arteriolar response}

346 Congestion of the venous system and subsequent increases in venous pressure, as 347 occurs during orthostasis, causes vasoconstriction upstream to the site of congestion 348 (Andersen et al., 1986; Henriksen et al., 1973; Skagen et al., 1982a; Skagen et al., 1982b). 349 The mechanism(s) by which this response occurs, termed the veno-arteriolar response, is 350 not entirely understood, although it is likely of local neural origin (Crandall et al., 2002; 351 Snyder et al., 2012; Vissing et al., 1997). Under normothermic conditions this veno352 arteriolar response is responsible for approximately $45 \%$ of the increase in systemic 353 vascular resistance during orthostasis (Henriksen, 1977; Henriksen et al., 1977). Given the 354 importance of increasing systemic vascular resistance during an orthostatic challenge, 355 coupled with findings of inadequate increases in systemic vascular resistance during such 356 a challenge while heat stressed (Ganio et al., 2012) (Figure 4), it may be that heat stress 357 compromises the veno-arteriolar response during venous congestion. This hypothesis was 358 evaluated by Brothers et al. (2009c) and Yamazaki et al. (2006) who showed that heat 359 stress attenuates the magnitude of cutaneous vasoconstriction when the veno-arteriolar 360 response was engaged via limb dependency, and subsequent increases in venous 361 pressure. Notably, the mechanism by which heat stress exerts this effect is unknown, but 362 may be related to altered pressure sensing in the cutaneous venous circulation and/or 363 altered vasoconstrictor responsiveness upstream to the pressure signal. Nevertheless, an 364 attenuated veno-arteriolar response during venous congestion associated with orthostasis 365 while heat stressed likely tempers increases in cutaneous vascular resistance that 366 otherwise would be beneficial in maintaining orthostatic tolerance.

\section{Cerebral vasculature}

369 Despite its small mass, the brain consumes nearly $20 \%$ of basal oxygen consumption 370 and thus has high oxygen and substrate delivery needs. Insufficient cerebral perfusion, and 371 thus oxygen delivery, is the primary mechanism for loss of consciousness during central 372 hypovolemia (Meendering et al., 2005; Van Lieshout et al., 2003). It is noteworthy that 373 passive heat stress itself reduces cerebral perfusion (Bain et al., 2013; Brothers et al., 
374 2009b; Fan et al., 2008; Fujii et al., 2008; Lucas et al., 2010; Lucas et al., 2008; Nelson et 375 al., 2011b; Ogoh et al., 2013; Ogoh et al., 2014; Ross et al., 2012; Schlader et al., 2013a; 376 Wilson et al., 2006; Wilson et al., 2002b); see the following citations for comprehensive 377 reviews on this topic (Bain et al., 2015; Crandall et al., 2014). After a threshold is achieved, 378 the magnitude of the reduction in cerebral perfusion is related to the severity of the heat 379 stress (Bain et al., 2015). For example, during mild to moderate heating, when internal 380 temperature increases between $\sim 0.5$ and $1.2^{\circ} \mathrm{C}$, cerebral perfusion either does not change 381 or only modestly decreases (Low et al., 2009; Lucas et al., 2008; Schlader et al., 2013a; 382 Wilson et al., 2006; Wilson et al., 2002b). However, further heating results in progressive 383 reductions in cerebral perfusion, such that $20-30 \%$ reductions in cerebral perfusion have 384 been noted when internal temperature is elevated greater than $1.5^{\circ} \mathrm{C}$ (Fan et al., 2008; Fujii 385 et al., 2008; Lee et al., 2013; Nelson et al., 2011b; Ross et al., 2012). The mechanisms 386 responsible for these reductions in cerebral perfusion can been attributed to three factors: 387 1) Reductions in mean arterial pressure associated with heat stress may reduce cerebral 388 perfusion pressure, which could reduce cerebral blood flow (Bain et al., 2013; Brothers et al., 2009b; Fan et al., 2008; Lee et al., 2013; Low et al., 2008; Lucas et al., 2008; Lucas et al., 2013b; Nelson et al., 2011b; Ogoh et al., 2013; Ross et al., 2012; Wilson et al., 2006). An argument against this however, is that cerebral autoregulation [i.e., the capacity of the 392 cerebral circulation to offset changes in perfusion pressure by intrinsic adjustments in 393 cerebrovascular resistance (Paulson et al., 1989)], is largely unaffected by heat stress 394 (Brothers et al., 2009d; Low et al., 2009). 2) Reductions in arterial carbon dioxide tension 395 associated with heat-induced hyperventilation lead to cerebrovascular vasoconstriction 396 (Bain et al., 2013; Brothers et al., 2009b; Fujii et al., 2008; Low et al., 2008; Nelson et al., 397 2011b; Ross et al., 2012). And 3) increases in cerebral sympathetic stimulation during heat 398 stress may induce cerebrovascular vasoconstriction (Brothers et al., 2009b).

399 Regardless of the mechanism, a reduction in cerebral perfusion by upwards to $30 \%$ 400 during heat stress will reduce the range by which cerebral perfusion could subsequently 401 decrease during an orthostatic challenge prior to syncope. This point is supported by 402 findings showing lower levels of cerebral perfusion for a given magnitude of orthostatic 403 stress when heat stressed (Lucas et al., 2008; Lucas et al., 2013a; Pearson et al., 2013; 404 Wilson et al., 2006), with cerebral perfusion at pre-syncope being similar between 405 normothermic and heat stressed conditions (Lucas et al., 2013a; Pearson et al., 2013). 406 Interestingly however, the magnitude of reductions in cerebral perfusion (as measured via 
407 middle cerebral artery blood flow velocity) to heat stress itself are not related to the

408 subsequent reductions in orthostatic tolerance relative to when normothermic (Lee et al., 409 2013). Furthermore, Lucas et al. (2013b) identified a disconnect between middle cerebral 410 artery blood flow velocity and orthostatic tolerance during heat stress, such that 411 administering 5\% carbon dioxide to the inspirate during orthostatic stress, which increased 412 cerebral blood flow back to pre-heat stress levels, did not improve orthostatic tolerance. 413 These findings suggest that heat-induced reductions in cerebral perfusion may not be 414 responsible for reduced orthostatic tolerance during heat stress. Alternatively however, it 415 may be that reductions in cerebral perfusion in the regions perfused by the middle cerebral 416 artery are not responsible for symptoms associated with pre-syncope. This speculation is 417 corroborated by data indicating differential cerebral blood flow regulation in the anterior 418 compared to the posterior circulations (Sato et al., 2012), but is contradicted by studies 419 demonstrating relationships between symptoms of pre-syncope and corresponding 420 reductions in middle cerebral artery blood velocity (Albina et al., 2004; Hermosillo et al., 421 2006). Furthermore, together with normothermic data (Lewis et al., 2014), these findings 422 may also suggest that cardiovascular adjustments may contribute more to orthostatic 423 tolerance than cerebral perfusion per se, the latter of which may be due to compensatory 424 increases in cerebral oxygen extraction (Bain et al., 2014; Bain et al., 2015).

425

426 Inter-individual differences in orthostatic tolerance during heat stress

427 Orthostatic tolerance varies between individuals during normothermia (Convertino et al., 428 2012; Convertino et al., 2000a; Convertino et al., 2000b; Greenleaf et al., 2000; Hinojosa429 Laborde et al., 2011; Levine et al., 1994; Rickards et al., 2011). As a result, there is great 430 interest in understanding inter-individual differences in orthostatic tolerance, with the hope 431 of developing strategies to improve such tolerance. Factors associated with greater 432 tolerance during orthostasis when normothermic are numerous and include an augmented 433 vasoactive hormone response (Convertino et al., 2000b; Greenleaf et al., 2000), higher 434 increases in vascular resistance (Convertino et al., 2012; Convertino et al., 2000b; Sather 435 et al., 1986), greater increases in heart rate (Convertino et al., 2012; Convertino et al., 436 2000a; Sather et al., 1986), enhanced protection of central blood volume and cerebral 437 perfusion (Levine et al., 1994), and augmented oscillations in blood pressure and cerebral 438 blood flow (Rickards et al., 2011). 
439 Despite that heat stress unanimously reduces orthostatic tolerance, inter-individual 440 differences in tolerance persist (Brothers et al., 2011; Lee et al., 2014; Lee et al., 2013; 441 Schlader et al., 2014a). Unfortunately, compared to the normothermic state, the 442 identification of factors determining inter-individual differences in orthostatic tolerance 443 during heat stress has proven relatively elusive. For instance, heat stress induced 444 reductions in central venous pressure (Brothers et al., 2011), reductions in cerebral 445 perfusion (Lee et al., 2013), the vasoactive hormone response (Lee et al., 2013), 446 cerebrovascular reactivity to carbon dioxide tension (Lee et al., 2014), differences in 447 aerobic fitness (Lee et al., 2013), and the increase in heart rate during orthostasis 448 (Schlader et al., 2014a) have all proven unable to explain inter-individual differences in 449 orthostatic tolerance during heat stress. To date, two factors have been identified that 450 explain at least a portion of the inter-individual variation in heat stressed orthostatic 451 tolerance. First, in a relatively large cohort of observations $(n=60)$, Schlader and Crandall 452 (2014a) identified that normothermic orthostatic tolerance partially predicts heat stressed 453 orthostatic tolerance, although it explains only $\sim 38 \%$ of the variance. Second, Cui et al. 454 (2011) identified that those individuals with the greatest increase in muscle sympathetic 455 nerve activity during orthostasis while heat stressed also had the highest orthostatic 456 tolerance under these conditions (Figure 5). Clearly, further research is required.

457 Potential differences in orthostatic tolerance during heat stress may also exist between 458 males and females or between younger and older adults. For instance, orthostatic 459 hypotension and orthostatic intolerance are paticularly prevelent in older adults (Rutan et 460 al., 1992). To our knowledge, no studies have systematically quantified orthostatic 461 tolerance during heat stress in older adults. During heat stress, older adults have 462 attenuated increases cardiac output (Greaney et al., 2015; Minson et al., 1998) and appear 463 utilize different strategies during combined heat and orthostatic stress, relying more on 464 increases in renal and splanchic vascular resistance, rather than increases in limb vascular 465 resistance (Minson et al., 1999). Older adults also exhibit greater reductions in cerebral 466 perfusion and slower corrections in blood pressure during orthostasis while heat stressed 467 (Lucas et al., 2008). This maybe due to age induced alterations in baroreflex function 468 (Monahan, 2007), which may also be present during heat and orthostatic stress (Greaney 469 et al., 2015; Shiraki et al., 1987). By contrast, the increase in muscle sympathetic nerve 470 activity during mild central hypovolemia while heat stressed is not affected by aging 471 (Gagnon et al., 2015a), which may ultimately explain why older adults are generally 
472 asympotomatic throughout combined heat and orthostatic stress (Lucas et al., 2008).

473 Collectively therefore, older adults may or may not have increased incidences orthostatic 474 intolerance during heat stress compared to a younger cohort.

475 Females have lower orthostatic tolerance than males during normothermia (Convertino, 476 1998; Montgomery et al., 1977; Waters et al., 2002), which is also true during heat stress 477 (Meendering et al., 2005). These observations are likely due to differential reliance on 478 neural and hemodynamic mechanisms to maintain blood pressure in females compared to 479 males (Hart et al., 2012) and/or differences in cardiac left ventricle size and alterations in 480 Frank-Starling relations (Fu et al., 2004). Importantly, no studies have examined if sex 481 modifies the magnitude by which heat stress reduces orthostatic tolerance. Clearly, more 482 formal research investigating sex differences is required to address these questions.

483

\section{4}

485

486

487

488

489

490 partially, via increased peripheral vascular resistance, increased ventricular filling pressures

\section{Countermeasures for improving orthostatic tolerance during heat stress}

Countermeasures for improving orthostatic tolerance during heat stress generally aim to reverse the central hypovolemic stress by augmenting central blood volume either directly (e.g., via volume expansion) or by increasing vascular resistance during orthostasis. For instance, in the supine position skin surface cooling, which is insufficient to change internal temperature, elicits peripheral (e.g., skin) and visceral (e.g., splanchnic, renal) vasocontriction and increases blood pressure (Cui et al., 2005; Wilson et al., 2007a). During orthostasis while normothermic, skin surface cooling increases central venous pressure and pulmonary capillary wedge pressure (Cui et al., 2005; Wilson et al., 2007b), reduces the magnitude of venous pooling (Durand et al., 2004), and increases blood pressure (Durand et al., 2004), all of which result in smaller reductions in stroke volume (Cui et al., 2005) and cerebral perfusion (Durand et al., 2004). As a result, normothermic orthostatic tolerance is improved by skin surface cooling (Durand et al., 2004). These findings have also been extended to heat stress, whereby rapid skin surface cooling increases central venous pressure, and reduces heart rate and cardiac output despite high prevaling internal temperatures (Rowell et al., 1969). Thus, heat stressed orthostatic tolerance is improved with skin surface cooling (Wilson et al., 2002b), which occurs, at least (Wilson et al., 2007b), and better maintenance of cerebral perfusion during orthostasis (Wilson et al., 2002b). 
504 Similar to skin surface cooling, acute volume expansion reverses heat stress induced 505 reductions in orthostatic tolerance (Figure 2) (Keller et al., 2009). As mentioned above, this 506 re-loading of the central vasculature (Bundgaard-Nielsen et al., 2010; Crandall et al., 2008) 507 augments cardiac output and stroke volume (Brothers et al., 2014), which better maintains 508 blood pressure during a given orthostatic stimulus (Keller et al., 2009; Schlader et al., 509 2013b). Thus, reductions in cerebral perfusion are attenuated during orthostasis under 510 such heat stressed and volume loaded circumstances (Schlader et al., 2013b).

511 Importantly, not all potential countermeasures are effective in alleviating reductions in 512 orthostatic tolerance during heat stress. For instance, as described above, reversal of heat 513 stress induced reductions in cerebral perfusion, via the introduction of carbon dioxide into 514 the inspirate, has no effect on orthostatic tolerance (Lucas et al., 2013b). These findings 515 suggest that interventions aimed specifically at the cerebral circulation, in the absence of 516 addressing systemic cardiovascular factors, may not be a viable countermeasure for 517 ensuring orthostatic tolerance during heat stress. Notably however, this hypothesis should 518 be tested further using different methods, as $5 \%$ inspired carbon dioxide may have also 519 exerted systemic effects that contributed to the impaired orthostatic tolerance.

520 Other countermeasures that are commonly employed to treat orthostatic intolerance in 521 clinical settings may also be effective during heat stress. These include drinking boluses of 522 water to initiate reflex vasoconstriction (Lu et al., 2003), which occurs via intragastric and 523 intraduodenal transient receptor potential vanilloid 4 channel activation (McHugh et al., 524 2010), activating the muscle pump via contracting muscles in the legs (e.g., applied muscle 525 tension), or increasing plasma volume via either increased salt intake or drug interventions 526 (e.g., vasopressors or minearlcorticoids) (Figueroa et al., 2010; Wieling et al., 2011). 527 Unfortunately however, the efficacy of these clinical countermeasures during heat stress 528 remains uncertain, and it cannot be assumed that these countermeasures will be effective 529 during heat stress. For instance, the cold pressor test, which induces large and robust 530 increases in blood pressure during normothermia, does not elicit as great of increases in 531 blood pressure during heat stress (Cui et al., 2010). Therefore, water drinking, which 532 elicites a moderate increase in blood pressure during normothermia (Lu et al., 2003), may 533 not be as effective under heat stress. However, it may also be that the sensitivity of 534 intragastric and intraduodenal receptor responses are unaffected by heat stress, resulting 535 in similar responses relative to that observed in normothermic individuals. Thus, research 
536 examining the effectiveness of simple and easily implimented orthostatic intolerance

537 countermeasures during heat stress is required.

538

\section{Conclusion}

540 It is clear that heat stress profoundly and unanimously reduces orthostatic tolerance. The 541 mechanisms underlying these observations are multifactorial and involve interactions 542 between multiple physiological systems. Potential factors include those associated with the 543 arterial and venous arms driving changes in vascular resistance and blood distribution, and 544 the modulation of cardiac output, all of which contribute to the inability to maintain cerebral 545 perfusion during heat and orthostatic stress. A number of countermeasures have been 546 established that aim to either alleviate heat stress induced central hypovolemia and/or 547 improve orthostasis induced increases in peripheral vascular resistance. Unfortunately, 548 these countermeasures are rather cumbersome to employ in clinical populations and acute 549 care occupational (e.g., military, mining) or injury (e.g., hemmorrhage) situations in which 550 heat stress and orthostatic stress or central hypovolemia are common. Thus, further 551 research is required to establish the effectiveness of simple, clinical countermeasures for 552 improving orthostatic tolerance during heat stress. Finally, identifying the mechanisms of 553 inter-individual differences in orthostatic intolerance during heat stress has proven relatively

554 elusive, but if understood these mechanisms could promote the development of novel and 555 personalized countermeasures for ensuring orthostatic tolerance during heat stress. Such 556 investigations should be considered of vital importance given global warming and the 557 impending increased incidence of heat events, which could have significant impacts on 558 cardiovascular health. 


\section{Acknowledements}

560 We would like to express gratitude to the NIH - National Heart, Lung, and Blood

561 Institute, the Department of Defense, NIOSH Education and Research Center, and the 562 American Heart Association for supporting much of our work presented in this review. 


\section{References}

566

567

568

569

570

571

572

573

574

575

576

577

578

579

580

581

582

583

584

585

586

587

588

589

590

591

592

593

594

595

596

597

598

599

Albina, G., Cisneros, L.F., Laiño, R., Nobo, U.L., Ortega, D., Schwarz, E., Barja, L., Lagos, R., Giniger, A., Ameriso, S.F. 2004. Transcranial Doppler monitoring during head upright tilt table testing in patients with suspected neurocardiogenic syncope. Europace 6, 63-69.

Allan, J., Crossley, R. 1972. Effect of controlled elevation of body temperature on human tolerance to $+G z$ acceleration. Journal of Applied Physiology 33, 418-420.

Andersen, E.B., Boesen, F., Henriksen, O., Sonne, M. 1986. Blood flow in skeletal muscle of tetraplegic man during postural changes. Clin Sci (Colch) 70, 321-325.

Anderson, B.G., Bell, M.L. 2009. Weather-related mortality: how heat, cold, and heat waves affect mortality in the United States. Epidemiol 20, 205.

Armstrong, L., Hubbard, R., Jones, B., Daniels, J. 1986. Preparing Alberto Salazar for the heat of the 1984 Olympic Marathon. Phys Sportsmed 14, 73-81.

Bain, A.R., Morrison, S.A., Ainslie, P.N. 2014. Cerebral oxygenation and hyperthermia. Frontiers in physiology 5 .

Bain, A.R., Nybo, L., Ainslie, P.N. 2015. Cerebral Vascular Control and Metabolism in Heat Stress. Comprehensive Physiology.

Bain, A.R., Smith, K.J., Lewis, N.C., Foster, G.E., Wildfong, K.W., Willie, C.K., Hartley, G.L., Cheung, S.S., Ainslie, P.N. 2013. Regional changes in brain blood flow during severe passive hyperthermia; the effects of $\mathrm{PaCO} 2$ and extra-cranial blood flow. J Appl Physiol $115,653-659$.

Bouchama, A., Knochel, J.P. 2002. Heat stroke. N Engl J Med 346, 1978-1988.

Brothers, R.M., Bhella, P.S., Shibata, S., Wingo, J.E., Levine, B.D., Crandall, C.G. 2009a. Cardiac systolic and diastolic function during whole body heat stress. American Journal of Physiology-Heart and Circulatory Physiology 296, H1150-H1156.

Brothers, R.M., Keller, D.M., Wingo, J.E., Ganio, M.S., Crandall, C.G. 2011. Heat-stressinduced changes in central venous pressure do not explain interindividual differences in orthostatic tolerance during heat stress. J Appl Physiol 110, 1283-1289.

Brothers, R.M., Pecini, R., Dalsgaard, M., Bundgaard-Nielsen, M., Wilson, T.E., Secher, N.H., Crandall, C.G. 2014. Beneficial effects of elevating cardiac preload on left-ventricular diastolic function and volume during heat stress: implications toward tolerance during a hemorrhagic insult. American Journal of Physiology-Regulatory, Integrative and Comparative Physiology 307, R1036-R1041.

Brothers, R.M., Wingo, J.E., Hubing, K.A., Crandall, C.G. 2009b. The effects of reduced end-tidal carbon dioxide tension on cerebral blood flow during heat stress. J Physiol 587, 3921-3927. 
600 Brothers, R.M., Wingo, J.E., Hubing, K.A., Del Coso, J., Crandall, C.G. 2009c. Effect of 601 whole body heat stress on peripheral vasoconstriction during leg dependency. J Appl 602 Physiol 107, 1704-1709.

603 Brothers, R.M., Zhang, R., Wingo, J.E., Hubing, K.A., Crandall, C.G. 2009d. Effects of heat 604 stress on dynamic cerebral autoregulation during large fluctuations in arterial blood 605 pressure. J Appl Physiol 107, 1722-1729.

606 Bundgaard-Nielsen, M., Wilson, T.E., Seifert, T., Secher, N.H., Crandall, C.G. 2010. Effect 607 of volume loading on the Frank-Starling relation during reductions in central blood volume 608 in heat-stressed humans. J Physiol 588, 3333-3339.

609 Convertino, V.A. 1998. Gender differences in autonomic functions associated with blood 610 pressure regulation. American Journal of Physiology-Regulatory, Integrative and 611 Comparative Physiology 275, R1909-R1920.

612 Convertino, V.A. 2014. Neurohumoral mechanisms associated with orthostasis: 613 reaffirmation of the significant contribution of the heart rate response. Frontiers in 614 physiology 5.

615 Convertino, V.A., Rickards, C.A., Ryan, K.L. 2012. Autonomic mechanisms associated with 616 heart rate and vasoconstrictor reserves. Clin Auton Res 22, 123-130.

617 Convertino, V.A., Sather, T.M. 2000a. Effects of cholinergic and beta-adrenergic blockade 618 on orthostatic tolerance in healthy subjects. Clin Auton Res 10, 327-336.

Convertino, V.A., Sather, T.M. 2000b. Vasoactive neuroendocrine responses associated with tolerance to lower body negative pressure in humans. Clin Physiol 20, 177-184.

621 Crandall, C., Johnson, J., Kosiba, W., Kellogg, D. 1996. Baroreceptor control of the 622 cutaneous active vasodilator system. Journal of Applied Physiology 81, 2192-2198.

623 Crandall, C.G. 2000. Carotid baroreflex responsiveness in heat-stressed humans. Am J 624 Physiol Heart Circ Physiol 279, H1955-1962.

625 Crandall, C.G. 2008. Heat stress and baroreflex regulation of blood pressure. Medicine and 626 science in sports and exercise 40, 2063.

627 Crandall, C.G., Cui, J., Wilson, T.E. 2003. Effects of heat stress on baroreflex function in 628 humans. Acta Physiol Scand 177, 321-328.

629 Crandall, C.G., Gonzalez-Alonso, J. 2010a. Cardiovascular function in the heat-stressed 630 human. Acta Physiol 199, 407-423.

631 Crandall, C.G., Shibasaki, M., Wilson, T.E. 2010b. Insufficient cutaneous vasoconstriction 632 leading up to and during syncopal symptoms in the heat stressed human. Am J Physiol 633 Heart Circ Physiol 299, H1168-1173.

634 Crandall, C.G., Shibasaki, M., Yen, T.C. 2002. Evidence that the human cutaneous 635 venoarteriolar response is not mediated by adrenergic mechanisms. J Physiol 538, 599636605. 
637 Crandall, C.G., Wilson, T.E. 2014. Human Cardiovascular Responses to Passive Heat 638 Stress. Comp Physiol.

Crandall, C.G., Wilson, T.E., Marving, J., Bundgaard-Nielsen, M., Seifert, T., Klausen, T., Andersen, F., Secher, N., Hesse, B. 2012. Colloid volume loading does not mitigate decreases in central blood volume during simulated hemorrhage while heat stressed. J Physiol 590, 1287-1297.

643 Crandall, C.G., Wilson, T.E., Marving, J., Vogelsang, T.W., Kjaer, A., Hesse, B., Secher, 644 N.H. 2008. Effects of passive heating on central blood volume and ventricular dimensions 645 in humans. J Physiol 586, 293-301.

646 Cui, J., Durand, S., Levine, B.D., Crandall, C.G. 2005. Effect of skin surface cooling on central venous pressure during orthostatic challenge. American Journal of PhysiologyHeart and Circulatory Physiology 289, H2429-H2433.

649 Cui, J., Shibasaki, M., Low, D.A., Keller, D.M., Davis, S.L., Crandall, C.G. 2010. Heat stress attenuates the increase in arterial blood pressure during the cold pressor test. J Appl 651 Physiol 109, 1354-1359.

652 Cui, J., Shibasaki, M., Low, D.A., Keller, D.M., Davis, S.L., Crandall, C.G. 2011. Muscle 653 sympathetic responses during orthostasis in heat-stressed individuals. Clinical Autonomic 654 Research 21, 381-387.

655 Cui, J., Wilson, T.E., Crandall, C.G. 2002. Baroreflex modulation of sympathetic nerve 656 activity to muscle in heat-stressed humans. Am J Physiol Regul Integr Comp Physiol 282, 657 R252-258.

658 Cui, J., Wilson, T.E., Crandall, C.G. 2004a. Muscle sympathetic nerve activity during lower 659 body negative pressure is accentuated in heat-stressed humans. Journal of Applied 660 Physiology 96, 2103-2108.

661 Cui, J., Wilson, T.E., Crandall, C.G. 2004b. Orthostatic challenge does not alter skin 662 sympathetic nerve activity in heat-stressed humans. Autonomic Neuroscience 116, 54-61.

663 Danet, S., Richard, F., Montaye, M., Beauchant, S., Lemaire, B., Graux, C., Cottel, D., 664 Marécaux, N., Amouyel, P. 1999. Unhealthy effects of atmospheric temperature and 665 pressure on the occurrence of myocardial infarction and coronary deaths a 10-year survey: 666 The lille-world health organization monica project. Circulation 100, e1-e7.

667 Davis, S.L., Crandall, C.G. 2010. Heat stress alters hemodynamic responses during the 668 Valsalva maneuver. Journal of Applied Physiology 108, 1591-1594.

669 Durand, S., Cui, J., Williams, K., Crandall, C. 2004. Skin surface cooling improves 670 orthostatic tolerance in normothermic individuals. American Journal of Physiology671 Regulatory, Integrative and Comparative Physiology 286, R199-R205.

672 Durand, S., Davis, S., Cui, J., Crandall, C. 2005. Exogenous nitric oxide inhibits 673 sympathetically mediated vasoconstriction in human skin. The Journal of physiology 562, 674 629-634. 
675 Easterling, D.R., Evans, J.L., Groisman, P.Y., Karl, T.R., Kunkel, K.E., Ambenje, P. 2000a.

676 Observed variability and trends in extreme climate events: a brief review. Bulletin of the

677 American Meteorological Society 81, 417-425.

678 Easterling, D.R., Meehl, G.A., Parmesan, C., Chagnon, S.A., Karl, T.R., Mearns, L.O.

679 2000b. Climate extremes: observations, modeling and impacts. Science 289, 2068-2074.

680 Esler, M. 2010. The 2009 Carl Ludwig Lecture: pathophysiology of the human sympathetic 681 nervous system in cardiovascular diseases: the transition from mechanisms to medical 682 management. Journal of Applied Physiology 108, 227-237.

683 Fan, J.L., Cotter, J.D., Lucas, R.A., Thomas, K., Wilson, L., Ainslie, P.N. 2008. Human 684 cardiorespiratory and cerebrovascular function during severe passive hyperthermia: effects 685

686 Figueroa, J.J., Basford, J.R., Low, P.A. 2010. Preventing and treating orthostatic 687 hypotension: as easy as A, B, C. Cleveland Clinic journal of medicine 77, 298.

688 Folland, C.K., Karl, T.R., Salinger, M.J. 2006. Observed climate variability and change. 689 Weather 57, 269-278.

690 Fu, Q., Arbab-Zadeh, A., Perhonen, M.A., Zhang, R., Zuckerman, J.H., Levine, B.D. 2004. 691 Hemodynamics of orthostatic intolerance: implications for gender differences. American 692

693

694

695

696

697 Journal of Physiology-Heart and Circulatory Physiology 286, H449-H457.

Fu, Q., Levine, B.D. 2014. Pathophysiology of neurally mediated syncope: Role of cardiac output and total peripheral resistance. Autonomic Neuroscience 184, 24-26.

Fu, Q., Shook, R.P., Okazaki, K., Hastings, J.L., Shibata, S., Conner, C.L., Palmer, M.D., Levine, B.D. 2006. Vasomotor sympathetic neural control is maintained during sustained upright posture in humans. The Journal of physiology $577,679-687$.

698 Fujii, N., Honda, Y., Hayashi, K., Kondo, N., Koga, S., Nishiyasu, T. 2008. Effects of 699 chemoreflexes on hyperthermic hyperventilation and cerebral blood velocity in resting 700

701

702

703

704

705

706

707

708

709 Gonzalez-Alonso, J., Crandall, C.G., Johnson, J.A. 2008. The cardiovascular challenge of 710 exercising in the heat. J Physiol 586, 45-53. 
711 Gorman, A.J., Proppe, D.W. 1984. Mechanisms producing tachycardia in conscious 712 baboons during environmental heat stress. Journal of Applied Physiology 56, 441-446.

713 Greaney, J.L., Stanhewicz, A.E., Proctor, D.N., Alexander, L.M., Kenney, W.L. 2015. 714 Impairments in central cardiovascular function contribute to attenuated reflex vasodilation in 715 aged skin. Journal of Applied Physiology, jap. 00729.02015.

716 Greenfield, A.D., Patterson, G.C. 1956. On the capacity and distensibility of the blood 717 vessels of the human forearm. J Physiol 131, 290-230+296.

718 Greenleaf, J.E., Petersen, T.W., Gabrielsen, A., Pump, B., Bie, P., Christensen, N.J., 719 Warberg, J., Videbaek, R., Simonson, S.R., Norsk, P. 2000. Low LBNP tolerance in men is 720 associated with attenuated activation of the renin-angiotensin system. Am J Physiol Regul 721 Integr Comp Physiol 279, R822-829.

722 Hagbarth, K.E., Hallin, R., Hongell, A., Torebjörk, H., Wallin, B. 1972. General 723 characteristics of sympathetic activity in human skin nerves. Acta Physiologica 724 Scandinavica 84, 164-176.

725 Hart, E.C., Joyner, M.J., Wallin, B.G., Charkoudian, N. 2012. Sex, ageing and resting blood 726 pressure: gaining insights from the integrated balance of neural and haemodynamic 727 factors. The Journal of physiology 590, 2069-2079.

728 Heinonen, I., Brothers, R.M., Kemppainen, J., Knuuti, J., Kalliokoski, K.K., Crandall, C.G. 729 2011. Local heating, but not indirect whole body heating, increases human skeletal muscle 730 blood flow. J Appl Physiol (1985) 111, 818-824.

731 Henriksen, O. 1977. Local sympathetic reflex mechanism in regulation of blood flow in 732 human subcutaneous adipose tissue. Acta Physiol Scand Supplement 450, 1-48.

733 Henriksen, O., Nielsen, S.L., Paaske, W.P., Sejrsen, P. 1973. Autoregulation of blood flow 734 in human cutaneous tissue. Acta Physiol Scand 89, 538-543.

735 Henriksen, O., Sejrsen, P. 1977. Local reflex in microcirculation in human skeletal muscle. 736 Acta Physiol Scand 99, 19-26.

737 Henry, J., Gauer, O. 1950. The influence of temperature upon venous pressure in the foot. 738 Journal of Clinical Investigation 29, 855.

739 Henry, J.P., Jacobs, H., Karstens, A., Gauer, O.H. 1949. Influence of temperature on the 740 pressure-volume. Am J Physiol 159, 573-574.

741 Hermosillo, A.G., Jordan, J.L., Vallejo, M., Kostine, A., Márquez, M.F., Cárdenas, M. 2006. 742 Cerebrovascular blood flow during the near syncopal phase of head-up tilt test: a 743 comparative study in different types of neurally mediated syncope. Europace 8, 199-203.

744 Hinojosa-Laborde, C., Rickards, C.A., Ryan, K.L., Convertino, V.A. 2011. Heart Rate 745 Variability during Simulated Hemorrhage with Lower Body Negative Pressure in High and 746 Low Tolerant Subjects. Front Physiol 2, 85. 
747 Hodges, G.J., Kosiba, W.A., Zhao, K., Alvarez, G.E., Johnson, J.M. 2007. The role of 748 baseline in the cutaneous vasoconstrictor responses during combined local and whole 749 body cooling in humans. American Journal of Physiology-Heart and Circulatory Physiology 750 293, H3187-H3192.

751 Horvath, S.M., Botelho, S.Y. 1949. Orthostatic hypotension following hot or cold baths. 752 Journal of applied physiology 1, 586-596.

753 Huynen, M.-M., Martens, P., Schram, D., Weijenberg, M.P., Kunst, A.E. 2001. The impact 754 of heat waves and cold spells on mortality rates in the Dutch population. Environ Health 755 Persp 109, 463.

756

757

758

759

760

761

762

763

764

765

766

767

768

769

770

771

772

773

774

775

776

777

778

779

780

781

782

783
Jose, A.D., Stitt, F., Collison, D. 1970. The effects of exercise and changes in body temperature on the intrinsic heart rate in man. American heart journal 79, 488-498.

Kaiser, R., Le Tertre, A., Schwartz, J., Gotway, C.A., Daley, W.R., Rubin, C.H. 2007. The effect of the 1995 heat wave in Chicago on all-cause and cause-specific mortality. Am J Public Health 97, S158-S162.

Keller, D., Cui, J., Davis, S., Low, D., Crandall, C. 2006. Heat stress enhances arterial baroreflex control of muscle sympathetic nerve activity via increased sensitivity of burst gating, not burst area, in humans. The Journal of physiology 573, 445-451.

Keller, D.M., Low, D.A., Wingo, J.E., Brothers, R.M., Hastings, J., Davis, S.L., Crandall, C.G. 2009. Acute volume expansion preserves orthostatic tolerance during whole-body heat stress in humans. J Physiol 587, 1131-1139.

Keller, D.M., Sander, M., Stallknecht, B., Crandall, C.G. 2010. $\alpha$ - Adrenergic vasoconstrictor responsiveness is preserved in the heated human leg. The Journal of Physiology 588, 3799-3808.

Kellogg, D. 2006. In vivo mechanisms of cutaneous vasodilation and vasoconstriction in humans during thermoregulatory challenges. Journal of Applied Physiology 100, 17091718.

Kenney, W.L., Craighead, D.H., Alexander, L.M. 2014a. Heat Waves, Aging and Human Cardiovascular Health. Med Sci Sport Exer 46, 1891-1899.

Kenney, W.L., Stanhewicz, A.E., Bruning, R.S., Alexander, L.M. 2014b. Blood pressure regulation III: what happens when one system must serve two masters: temperature and pressure regulation? Eur J Appl Physiol 114, 467-479.

Klabunde, R.E., LePorte, A.D., Wilson, T.E. 2013. Effect of temperature on isoproterenolinduced increases in left ventricular developed pressure. Journal of Thermal Biology 38, 369-373.

Knowlton, K., Rotkin-Ellman, M., King, G., Margolis, H.G., Smith, D., Solomon, G., Trent, R., English, P. 2009. The 2006 California heat wave: impacts on hospitalizations and emergency department visits. Environ Health Persp 117, 61. 
784 Krogh, A. 1912. The Regulation of the Supply of Blood to the Right Heart1. 785 Skandinavisches Archiv Für Physiologie 27, 227-248.

786 Lee, J.F., Christmas, K.M., Harrison, M.L., Hurr, C., Kim, K., Brothers, R.M. 2014. 787 Variability in Orthostatic Tolerance During Heat Stress: Cerebrovascular Reactivity to 788 Arterial Carbon Dioxide. Aviation, space, and environmental medicine 85, 624-630.

789 Lee, J.F., Harrison, M.L., Brown, S.R., Brothers, R.M. 2013. The magnitude of heat stress790 induced reductions in cerebral perfusion does not predict heat stress-induced reductions in 791 tolerance to a simulated hemorrhage. J Appl Physiol 114, 37-44.

792 Levine, B.D. 1993. Regulation of central blood volume and cardiac filling in endurance 793 athletes: the Frank-Starling mechanism as a determinant of orthostatic tolerance. Medicine 794 and science in sports and exercise 25, 727-732.

795 Levine, B.D., Giller, C.A., Lane, L.D., Buckey, J.C., Blomqvist, C.G. 1994. Cerebral versus 796 systemic hemodynamics during graded orthostatic stress in humans. Circulation 90, 298797306.

798 Lewis, N., Bain, A.R., MacLeod, D.B., Wildfong, K.W., Smith, K.J., Willie, C.K., Sanders, 799 M.L., Numan, T., Morrison, S.A., Foster, G.E. 2014. Impact of hypocapnia and cerebral 800 perfusion on orthostatic tolerance. The Journal of physiology 592, 5203-5219.

801 Lind, A.R., Leithead, C.S., McNicol, G.W. 1968. Cardiovascular changes during syncope 802 induced by tilting men in the heat. J Appl Physiol 25, 268-276.

803 Low, D.A., Keller, D.M., Wingo, J.E., Brothers, R.M., Crandall, C.G. 2011. Sympathetic 804 nerve activity and whole body heat stress in humans. J Appl Physiol 111, 1329-1334.

805 Low, D.A., Shibasaki, M., Davis, S.L., Keller, D.M., Crandall, C.G. 2007. Does local 806 heating-induced nitric oxide production attenuate vasoconstrictor responsiveness to lower 807 body negative pressure in human skin? Journal of Applied Physiology 102, 1839-1843.

808 Low, D.A., Wingo, J.E., Keller, D.M., Davis, S.L., Cui, J., Zhang, R., Crandall, C.G. 2009. 809 Dynamic cerebral autoregulation during passive heat stress in humans. American Journal 810 of Physiology: Regulatory, Integrative and Comparative Physiology 296, R1598-1605.

811 Low, D.A., Wingo, J.E., Keller, D.M., Davis, S.L., Zhang, R., Crandall, C.G. 2008. 812 Cerebrovascular responsiveness to steady-state changes in end-tidal CO2 during passive 813 heat stress. Journal of Applied Physiology 104, 976-981.

814 Lu, C.-C., Diedrich, A., Tung, C.-S., Paranjape, S.Y., Harris, P.A., Byrne, D.W., Jordan, J., 815 Robertson, D. 2003. Water ingestion as prophylaxis against syncope. Circulation 108, 816 2660-2665.

817 Lucas, R.A., Ainslie, P.N., Fan, J.L., Wilson, L.C., Thomas, K.N., Cotter, J.D. 2010. Skin 818 cooling aids cerebrovascular function more effectively under severe than moderate heat 819 stress. Eur J Appl Physiol 109, 101-108. 
820 Lucas, R.A., Cotter, J.D., Morrison, S., Ainslie, P.N. 2008. The effects of ageing and 821 passive heating on cardiorespiratory and cerebrovascular responses to orthostatic stress in 822 humans. Exp Physiol 93, 1104-1117.

823 Lucas, R.A., Ganio, M.S., Pearson, J., Crandall, C.G. 2013a. Sweat loss during heat stress 824 contributes to subsequent reductions in lower - body negative pressure tolerance. Exp 825 Physiol 98, 473-480.

826 Lucas, R.A., Pearson, J., Schlader, Z.J., Crandall, C.G. 2013b. Hypercapnia-induced 827 increases in cerebral blood flow do not improve lower body negative pressure tolerance 828 during hyperthermia. Am J Physiol Regul Integr Comp Physiol 305, R604-R609.

829 Lucas, R.A., Sarma, S., Schlader, Z.J., Pearson, J., Crandall, C.G. 2015. Age - related 830 changes to cardiac systolic and diastolic function during whole - body passive 831 hyperthermia. Exp Physiol 100, 422-434.

832 Mack, G.W., Nadel, E.R. 2011. Body fluid balance during heat stress in humans. 833 Comprehensive Physiology Supplement 14: Handbook of Physiology, Environmental 834 Physiology, 187-214.

835 Mano, T., Iwase, S. 2003. Sympathetic nerve activity in hypotension and orthostatic 836 intolerance. Acta physiologica scandinavica 177, 359-365.

840

841

842

843

844

845

846

847 848

849

850

851

852

853

854

855

856

McHugh, J., Keller, N.R., Appalsamy, M., Thomas, S.A., Raj, S.R., Diedrich, A., Biaggioni, I., Jordan, J., Robertson, D. 2010. Portal osmopressor mechanism linked to transient receptor potential vanilloid 4 and blood pressure control. Hypertension 55, 1438-1443.

Meehl, G.A., Stocker, T.F., Collins, W.D., Friedlingstein, P., Gaye, A.T., Gregory, J.M., Kitoh, A., Knutti, R., Murphy, J.M., Noda, A., Raper, S.C.B., Watterson, I.G., Weaver, A.J., Zhao, Z.C. 2007. Global Climate Projections. In: Solomon, S., Qin, D., Manning, M., Chen, Z., Marquis, M., Averyt, K.B., Tignor, M., Miller, H.L., (Eds.), Climate Change 2007: The Physical Science Basis. Contribution of Working Group I to the Fourth Assessment Report of the Intergovernmental Panel on Climate Change Cambridge University Press, Cambridge, U.K.

Meehl, G.A., Tebaldi, C. 2004. More intense, more frequent, and longer lasting heat waves in the 21 st century. Science $305,994-997$.

Meendering, J.R., Torgrimson, B.N., Houghton, B.L., Halliwill, J.R., Minson, C.T. 2005. Menstrual cycle and sex affect hemodynamic responses to combined orthostatic and heat stress. Am J Physiol Heart Circ Physiol 289, H631-642.

Minson, C.T., Wladkowski, S.L., Cardell, A.F., Pawelczyk, J.A., Kenney, W.L. 1998. Age alters the cardiovascular response to direct passive heating. J Appl Physiol 84, 1323-1332.

Minson, C.T., Wladkowski, S.L., Pawelczyk, J.A., Kenney, W.L. 1999. Age, splanchnic vasoconstriction, and heat stress during tilting. Am J Physiol Regul Integr Comp Physiol 276, R203-212. 
857 Monahan, K.D. 2007. Effect of aging on baroreflex function in humans. American Journal of 858 Physiology-Regulatory, Integrative and Comparative Physiology 293, R3-R12.

859

860

861

862

863

864

865

866

867

868

869

870

871

872

873

874

875

876

877

878

879

880

881

882

883

884

885

886

887

888

889

890

891

892

893

894

Montgomery, L.D., Kirk, P.J., Payne, P.A., Gerber, R.L., Newton, S., Williams, B. 1977. Cardiovascular responses of men and women to lower body negative pressure. Aviation, space, and environmental medicine 48, 138-145.

Nelson, M.D., Altamirano-Diaz, L.A., Petersen, S.R., DeLorey, D.S., Stickland, M.K., Thompson, R.B., Haykowsky, M.J. 2011a. Left ventricular systolic and diastolic function during tilt-table positioning and passive heat stress in humans. American Journal of Physiology-Heart and Circulatory Physiology 301, H599-H608.

Nelson, M.D., Haykowsky, M.J., Petersen, S.R., DeLorey, D.S., Cheng-Baron, J., Thompson, R.B. 2010. Increased left ventricular twist, untwisting rates, and suction maintain global diastolic function during passive heat stress in humans. American Journal of Physiology-Heart and Circulatory Physiology 298, H930-H937.

Nelson, M.D., Haykowsky, M.J., Stickland, M.K., Altamirano-Diaz, L.A., Willie, C.K., Smith, K.J., Petersen, S.R., Ainslie, P.N. 2011b. Reductions in cerebral blood flow during passive heat stress in humans: partitioning the mechanisms. J Physiol 589, 4053-4064.

Niimi, Y., Matsukawa, T., Sugiyama, Y., Shamsuzzaman, A., Ito, H., Sobue, G., Mano, T. 1997. Effect of heat stress on muscle sympathetic nerve activity in humans. Journal of the autonomic nervous system 63, 61-67.

Normell, L.A., Wallin, B.G. 1974. Sympathetic skin nerve activity and skin temperature changes in man. Acta physiologica Scandinavica 91, 417-426.

Nunneley, S.A., Stribley, R.F. 1979. Heat and acute dehydration effects on acceleration response in man. Journal of Applied Physiology 47, 197-200.

Ogoh, S., Sato, K., Okazaki, K., Miyamoto, T., Hirasawa, A., Morimoto, K., Shibasaki, M. 2013. Blood flow distribution during heat stress: cerebral and systemic blood flow. J Cereb Blood Flow Metab 33, 1915-1920.

Ogoh, S., Sato, K., Okazaki, K., Miyamoto, T., Hirasawa, A., Shibasaki, M. 2014. Hyperthermia modulates regional differences in cerebral blood flow to changes in $\mathrm{CO} 2$. Journal of applied physiology 117, 46-52.

Organization, W.M. 2015. Warming trend continues in 2014, hottest year on record, Genva, Switzerland.

Paulson, O., Strandgaard, S., Edvinsson, L. 1989. Cerebral autoregulation. Cerebrovascular and brain metabolism reviews 2, 161-192.

Pearson, J., Ganio, M.S., Lucas, R.A., Babb, T.G., Crandall, C.G. 2013. Heat stress does not augment ventilatory responses to presyncopal limited lower body negative pressure. Exp Physiol 98, 1156-1163.

Pearson, J., Low, D.A., Stohr, E., Kalsi, K., Ali, L., Barker, H., Gonzalez-Alonso, J. 2011. Hemodynamic responses to heat stress in the resting and exercising human leg: insight 
895 into the effect of temperature on skeletal muscle blood flow. Am J Physiol Regul Integr 896 Comp Physiol 300, R663-673.

897 Pearson, J., Lucas, R.A., Schlader, Z.J., Zhao, J., Gagnon, D., Crandall, C.G. 2014. Active 898 and passive heat stress similarly compromise tolerance to a simulated hemorrhagic 899 challenge. Am J Physiol Regul Integr Comp Physiol 307, R822-R827.

900 Ratcliffe, R.A.S., Weller, J., Collison, P. 2006. Variability in the frequency of unusual 901 weather over approximately the last century. Quarterly Journal of the Royal Meteorological 902 Society 104, 243-255.

903 Rickards, C.A., Ryan, K.L., Cooke, W.H., Convertino, V.A. 2011. Tolerance to central 904 hypovolemia: the influence of oscillations in arterial pressure and cerebral blood velocity. $J$ 905 Appl Physiol 111, 1048-1058.

906 Ross, E.Z., Cotter, J.D., Wilson, L., Fan, J.L., Lucas, S.J., Ainslie, P.N. 2012. 907 Cerebrovascular and corticomotor function during progressive passive hyperthermia in 908 humans. J Appl Physiol 112, 748-758.

909 Rowell, L. 1983. Cardiovascular aspects of human thermoregulation. Circulation Research $910 \quad 52,367-379$.

911 Rowell, L. 1990. Hyperthermia: a hyperadrenergic state. Hypertension 15, 505-507.

912 Rowell, L.B. 1974. Human Cardiovascular Adjustments to Exercise and Thermal-Stress. 913 Physiol Rev 54, 75-159.

914 Rowell, L.B. 1986a. Cutaneous and skeletal muscle circulations, Human Circulation 915 Regulation During Physical Stress. Oxford University Press, New York. pp. 96-116.

916 Rowell, L.B. 1986b. Thermal Stress, Human Circulation Regulation During Physical Stress. 917 Oxford Univeristy Press, New York. pp. 174-212.

918 Rowell, L.B., Brengelmann, G.L., Blackmon, J.R., Twiss, R.D., Kusumi, F. 1968. 919 Splanchnic blood flow and metabolism in heat-stressed man. J Appl Physiol 24, 475-484.

920 Rowell, L.B., Brengelmann, G.L., Detry, J., Wyss, C. 1971a. Venomotor responses to local 921 and remote thermal stimuli to skin in exercising man. Journal of applied physiology 30, 7292277.

923 Rowell, L.B., Brengelmann, G.L., Murray, J.A. 1969. Cardiovascular responses to 924 sustained high skin temperature in resting man. J Appl Physiol 27, 673-680.

925 Rowell, L.B., Detry, J.R., Profant, G.R., Wyss, C. 1971b. Splanchnic vasoconstriction in 926 hyperthermic man - role of falling blood pressure. J Appl Physiol 31, 864-869.

927 Rutan, G.H., Hermanson, B., Bild, D.E., Kittner, S.J., LaBaw, F., Tell, G.S. 1992. 928 Orthostatic hypotension in older adults. The Cardiovascular Health Study. CHS 929 Collaborative Research Group. Hypertension 19, 508-519. 
930 Sather, T.M., Goldwater, D.J., Montgomery, L.D., Convertino, V.A. 1986. Cardiovascular 931 dynamics associated with tolerance to lower body negative pressure. Aviat Space Environ 932 Med 57, 413-419.

933 Sato, K., Fisher, J.P., Seifert, T., Overgaard, M., Secher, N.H., Ogoh, S. 2012. Blood flow 934 in internal carotid and vertebral arteries during orthostatic stress. Experimental physiology 935 97, 1272-1280.

936 Schlader, Z.J., Crandall, C.G. 2014a. Normothermic central hypovolemia tolerance reflects 937 hyperthermic tolerance. Clin Auton Res 24, 119-126.

938 Schlader, Z.J., Gagnon, D., Rivas, E., Convertino, V.A., Crandall, C.G. 2015. Fluid 939 restriction during exercise in the heat reduces tolerance to progressive central 940 hypovolemia. Exp Physiol.

941 Schlader, Z.J., Lucas, R.A., Pearson, J., Crandall, C.G. 2013a. Hyperthermia does not alter 942 the increase in cerebral perfusion during cognitive activation. Exp Physiol 98, 1597-1607.

943 Schlader, Z.J., Rivas, E., Soller, B.R., Convertino, V.A., Crandall, C.G. 2014b. Tissue 944 oxygen saturation during hyperthermic progressive central hypovolemia. Am J Physiol 945 Regul Integr Comp Physiol 307, R731-R736.

946 Schlader, Z.J., Seifert, T., Wilson, T.E., Bundgaard-Nielsen, M., Secher, N.H., Crandall, 947 C.G. 2013b. Acute volume expansion attenuates hyperthermia-induced reductions in 948 cerebral perfusion during simulated hemorrhage. J Appl Physiol 114, 1730-1735.

949 Schwartz, C.E., Stewart, J.M. 2012. The arterial baroreflex resets with orthostasis. 950 Frontiers in physiology 3.

951 Shibasaki, M., Davis, S.L., Cui, J., Low, D.A., Keller, D.M., Durand, S., Crandall, C.G. 2006. 952 Neurally mediated vasoconstriction is capable of decreasing skin blood flow during 953 orthostasis in the heat - stressed human. The Journal of physiology 575, 953-959.

954 Shibasaki, M., Durand, S., Davis, S.L., Cui, J., Low, D.A., Keller, D.M., Crandall, C.G. 2007. 955 Endogenous nitric oxide attenuates neutrally mediated cutaneous vasoconstriction. The 956 Journal of physiology 585, 627-634.

957 Shibasaki, M., Low, D.A., Davis, S.L., Crandall, C.G. 2008. Nitric oxide inhibits cutaneous 958 vasoconstriction to exogenous norepinephrine. Journal of applied physiology 105, 15049591508.

960 Shibasaki, M., Umemoto, Y., Kinoshita, T., Kouda, K., Ito, T., Nakamura, T., Crandall, C.G., 961 Tajima, F. 2015. The role of cardiac sympathetic innervation and skin thermoreceptors on 962 cardiac responses during heat stress. Am J Physiol Heart Circ Physiol, ajpheart. 96300911.02014.

964 Shiraki, K., Sagawa, S., Yousef, M., Konda, N., Miki, K. 1987. Physiological responses of 965 aged men to head-up tilt during heat exposure. Journal of Applied Physiology 63, 576-581.

966 Shvartz, E., Meyerstein, N. 1970. Effect of heat and natural acclimatization to heat on tilt 967 tolerance of men and women. Journal of applied physiology $28,428-432$. 
968 Skagen, K., Bonde-Petersen, F. 1982a. Regulation of subcutaneous blood flow during 969 head-up tilt $\left(45^{\circ}\right)$ in normals. Acta Physiol Scand 114, 31-35.

970 Skagen, K., Jensen, K., Henriksen, O., Knudsen, L. 1982b. Sympathetic reflex control of 971 subcutaneous blood flow in tetraplegic man during postural changes. Clin Sci (Colch) 62, 972 605-609.

973 Snyder, K.A., Shamimi - Noori, S., Wilson, T.E., Monahan, K.D. 2012. Age - and limb 974 related differences in the vasoconstrictor response to limb dependency are not mediated by 975 a sympathetic mechanism in humans. Acta Physiol 205, 372-380.

976 Stöhr, E.J., González - Alonso, J., Pearson, J., Low, D.A., Ali, L., Barker, H., Shave, R. 977 2011. Effects of graded heat stress on global left ventricular function and twist mechanics 978 at rest and during exercise in healthy humans. Experimental physiology 96, 114-124.

979 Van Lieshout, J.J., Wieling, W., Karemaker, J.M., Secher, N.H. 2003. Syncope, cerebral 980 perfusion, and oxygenation. J Appl Physiol 94, 833-848.

981 Vandecasteele, G., Eschenhagen, T., Scholz, H., Stein, B., Verde, I., Fischmeister, R. 982 1999. Muscarinic and $\beta$-adrenergic regulation of heart rate, force of contraction and calcium 983 current is preserved in mice lacking endothelial nitric oxide synthase. Nature medicine 5 , 984 331-334.

985 Vandentorren, S., Bretin, P., Zeghnoun, A., Mandereau-Bruno, L., Croisier, A., Cochet, C., 986 Ribéron, J., Siberan, I., Declercq, B., Ledrans, M. 2006. August 2003 heat wave in France: 987

988 risk factors for death of elderly people living at home. Eur J Pub Health 16, 583-591.

989

Vanhoutte, P.M., Shepherd, J.T. 1970. Effect of temperature on reactivity of isolated cutaneous veins of the dog. Am J Physiol 218, 187-190.

990 Vissing, S., Secher, N., Victor, R. 1997. Mechanisms of cutaneous vasoconstriction during 991 upright posture. Acta physiologica Scandinavica 159, 131-138.

992 Wallin, B.G., Sundlöf, G., Delius, W. 1975. The effect of carotid sinus nerve stimulation on 993 muscle and skin nerve sympathetic activity in man. Pflügers Archiv 358, 101-110.

994 Waters, W.W., Ziegler, M.G., Meck, J.V. 2002. Postspaceflight orthostatic hypotension 995 occurs mostly in women and is predicted by low vascular resistance. Journal of Applied 996 Physiology 92, 586-594.

997 Webb-Peploe, M.M. 1969. Effect of changes in central body temperature on capacity 998 elements of limb and spleen. Am J Physiol 216, 643-646.

999 Webb-Peploe, M.M., Shepherd, J.T. 1968a. Peripheral mechanism involved in response of 1000 dog's cutaneous veins to local temperature change. Circ Res 23, 701-708.

1001 Webb-Peploe, M.M., Shepherd, J.T. 1968b. Response of dogs' cutaneous veins to local 1002 and central temperature changes. Circ Res 23, 693-699. 
1003 Wieling, W., France, C.R., van Dijk, N., Kamel, H., Thijs, R.D., Tomasulo, P. 2011. 1004 Physiologic strategies to prevent fainting responses during or after whole blood donation. 1005 Transfusion 51, 2727-2738.

1006 Wilson, T., Brothers, R., Tollund, C., Dawson, E., Nissen, P., Yoshiga, C., Jons, C., Secher, 1007 N.H., Crandall, C. 2009a. Effect of thermal stress on Frank-Starling relations in humans. 1008 The Journal of physiology 587, 3383-3392.

1009 Wilson, T.E., Brothers, R.M., Tollund, C., Dawson, E.A., Nissen, P., Yoshiga, C.C., Jons, 1010 C., Secher, N.H., Crandall, C.G. 2009b. Effect of thermal stress on Frank-Starling relations 1011 in humans. J Physiol 587, 3383-3392.

1012 Wilson, T.E., Cui, J., Crandall, C.G. 2001. Absence of arterial baroreflex modulation of skin 1013 sympathetic activity and sweat rate during whole - body heating in humans. The Journal of 1014 physiology 536, 615-623.

1015 Wilson, T.E., Cui, J., Crandall, C.G. 2002a. Effect of whole-body and local heating on 1016 cutaneous vasoconstrictor responses in humans. Auton Neurosci 97, 122-128.

1017 Wilson, T.E., Cui, J., Crandall, C.G. 2005. Mean body temperature does not modulate 1018 eccrine sweat rate during upright tilt. Journal of Applied Physiology 98, 1207-1212.

1019 Wilson, T.E., Cui, J., Zhang, R., Crandall, C.G. 2006. Heat stress reduces cerebral blood 1020 velocity and markedly impairs orthostatic tolerance in humans. Am J Physiol Regul Integr 1021 Comp Physiol 291, R1443-1448.

1022 Wilson, T.E., Cui, J., Zhang, R., Witkowski, S., Crandall, C.G. 2002b. Skin cooling 1023 maintains cerebral blood flow velocity and orthostatic tolerance during tilting in heated 1024 humans. J Appl Physiol 93, 85-91.

1025 Wilson, T.E., Sauder, C.L., Kearney, M.L., Kuipers, N.T., Leuenberger, U.A., Monahan, 1026 K.D., Ray, C.A. 2007a. Skin-surface cooling elicits peripheral and visceral vasoconstriction 1027 in humans. J Appl Physiol 103, 1257-1262.

1028 Wilson, T.E., Tollund, C., Yoshiga, C.C., Dawson, E.A., Nissen, P., Secher, N.H., Crandall, 1029 C.G. 2007b. Effects of heat and cold stress on central vascular pressure relationships 1030 during orthostasis in humans. J Physiol 585, 279-285.

1031 Yamazaki, F., Monji, K., Sogabe, Y., Sone, R. 2000. Cardiac and peripheral vascular 1032 responses to head-up tilt during whole body thermal stress. Journal of UOEH 22, 147-158.

1033 Yamazaki, F., Nakayama, Y., Sone, R. 2006. Whole-body heating decreases skin vascular 1034 response to low orthostatic stress in the lower extremities. J Physiol Sci 56, 157-164.

1035 Yamazaki, F., Okuno, C., Nagamatsu, S., Sone, R. 2002. Effects of whole-body and local 1036 thermal stress on hydrostatic volume changes in the human calf. European journal of 1037 applied physiology 88, 61-66.

1038 Yamazaki, F., Yamauchi, K., Tsutsui, Y., Endo, Y., Sagawa, S., Shiraki, K. 2003. Whole 1039 body heating reduces the baroreflex response of sympathetic nerve activity during Valsalva 1040 straining. Autonomic Neuroscience 103, 93-99. 
1041 Zitnik, R.S., Ambrosioni, E., Shepherd, J.T. 1971. Effect of temperature on cutaneous 1042 venomotor reflexes in man. J Appl Physiol 31, 507-512.

1043 


\section{Figures}

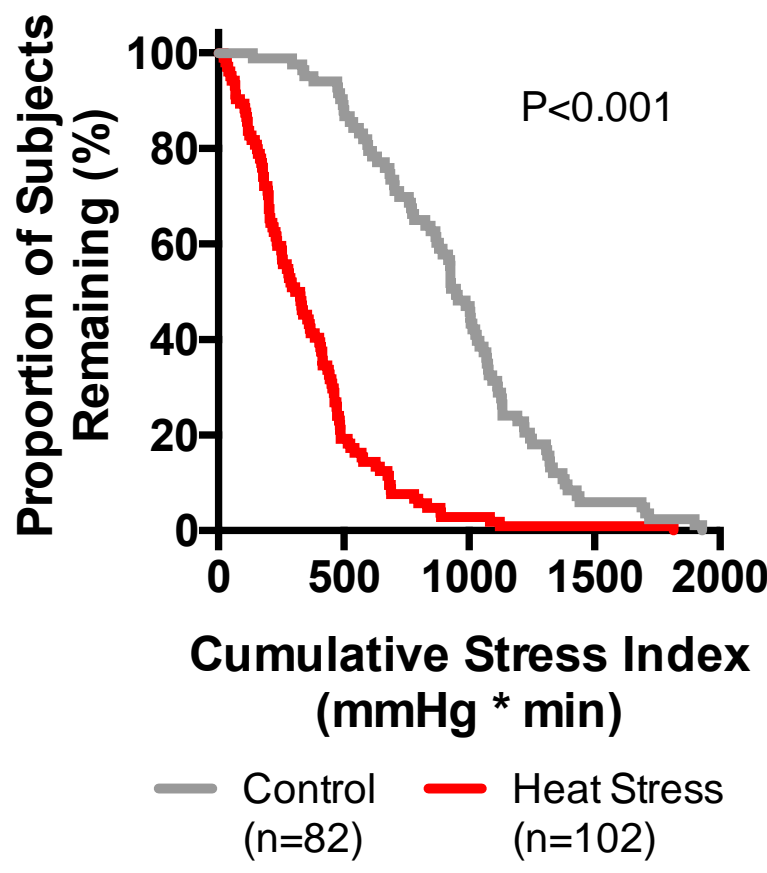

Figure 1: Orthostatic tolerance during lower body negative pressure, quantified via the 1047 cumulative stress index (see text), is unanimously reduced by passive heat stress sufficient 1048 to increase internal temperature by a mean of $\sim 1.4^{\circ} \mathrm{C}$. 


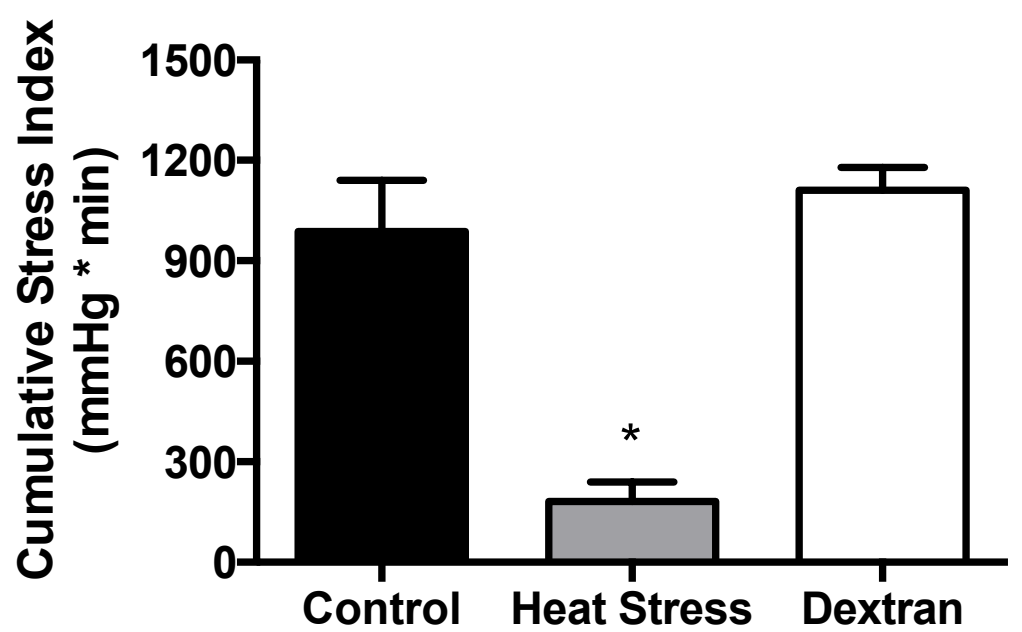

1051 Figure 2: Heat stress induced orthostatic intolerance during lower body negative pressure, 1052 quantified via the cumulative stress index (see text), is restored by volume expansion via a 1053 dextran solution (mean $\pm \mathrm{SD}, \mathrm{n}=7)$. * different from Control and Dextran $(\mathrm{P}<0.05)$. Figure 1054 redrawn from Keller et al. (2009), with permission. 

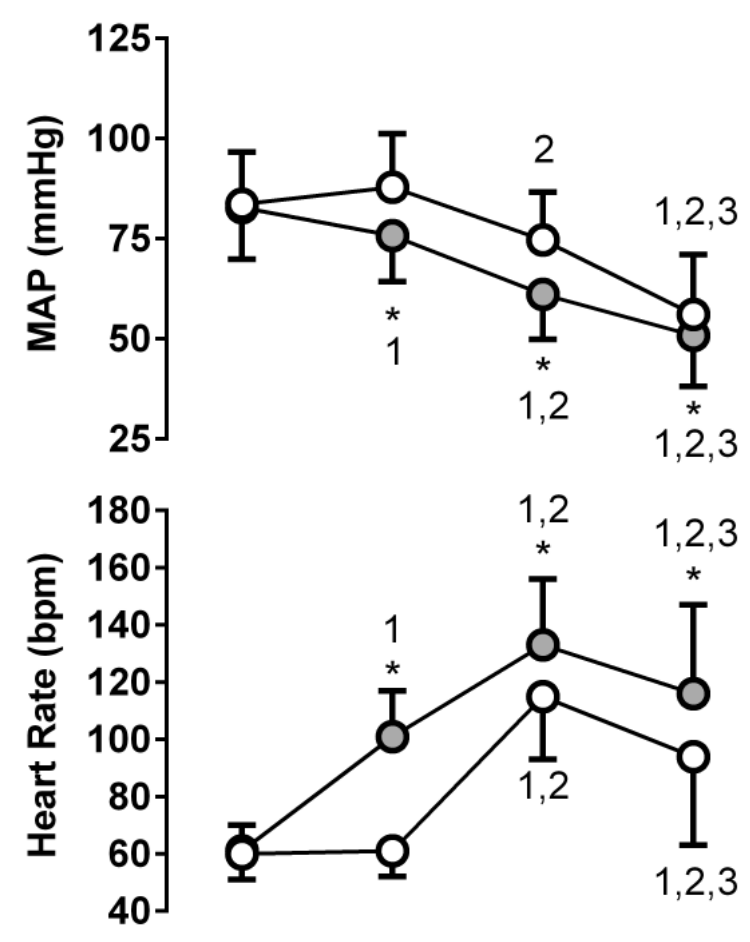

1057 Figure 3: Mean arterial pressure (MAP, top), heart rate (middle), and the change $(\Delta)$ in 1058 heart rate from Pre- lower body negative pressure (LBNP, bottom) during normothermic 1059 and heat stressed LBNP pre- thermal perturbation (Baseline), immediately prior to 1060 commending LBNP (Pre-LBNP), the highest heart rate achieved during the final 2 min of 1061 LBNP (i.e., prior to any bradycardia, Peak-LBNP), and immediately prior to LBNP 1062 termination (Pre-Syncope) (mean $\pm S D, n=60$ ). Despite greater absolute heart rates during 1063 heat stress, the increase in heart rate during LBNP is attenuated with heat stress despite 1064 greater reductions in arterial pressure. * indicates different from Normothermia $(P \leq 0.029)$; 
1065 1, 2, and 3, indicate different from Baseline, Pre-LBNP, and Peak-LBNP, respectively 1066 ( $\mathrm{P} \leq 0.018)$. Figure redrawn from Schlader and Crandall $(2014 \mathrm{a})$, with permission. 


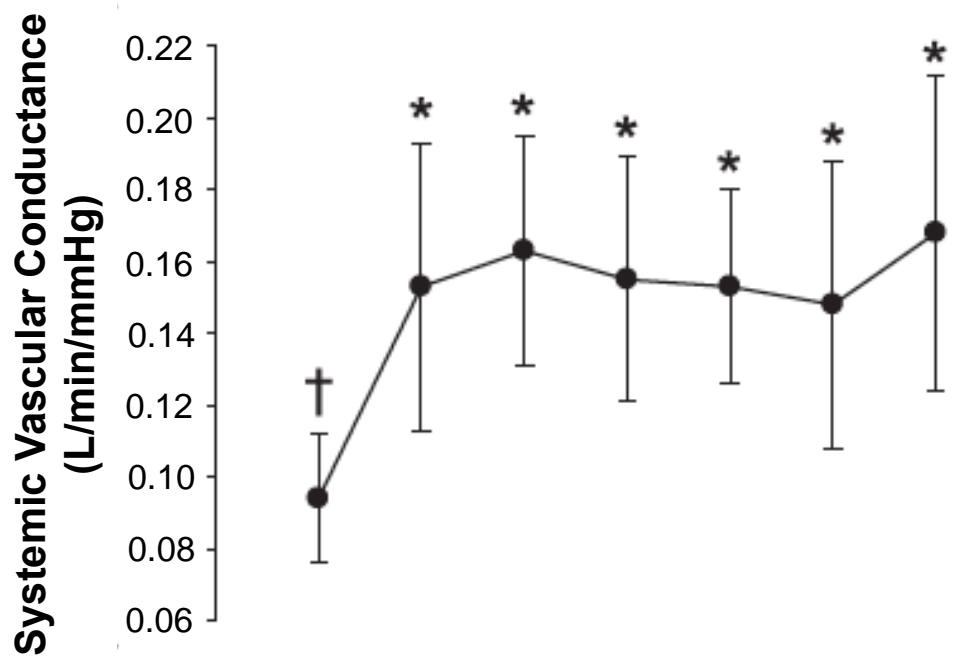

1068

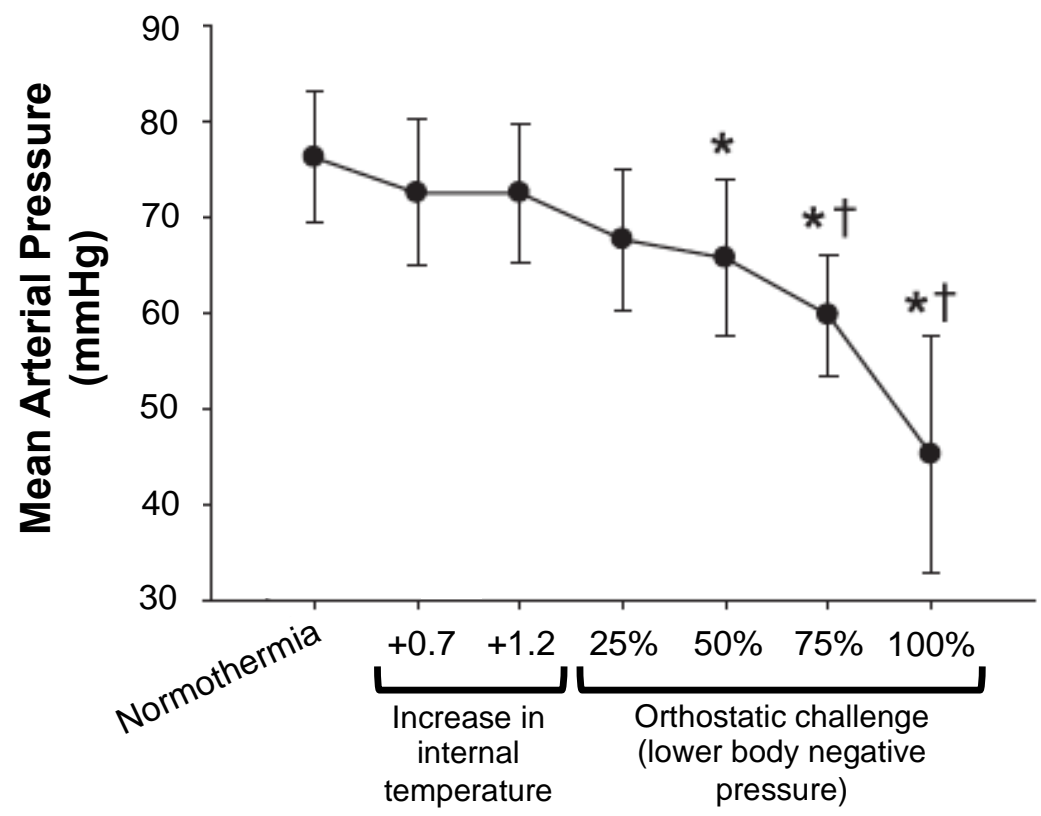

1069 Figure 4: Systemic vascular conductance (top), the inverse of vascular resistance, and 1070 mean arterial pressure (bottom), during normothermia, passive heat stress, and throughout 1071 an orthostatic challenge (i.e., lower body negative pressure) to pre-syncope (100\%) while 1072 heat stressed (mean $\pm S D, n=11$ ). Under heat stressed during orthostasis, despite profound 1073 hypotension, systemic vascular conductance was not reduced. Systemic vascular 1074 conductance was calculated as the quotient of thermodilution derived cardiac output 1075 measurements and mean arterial pressure. * different from Normothermia $(P<0.05)$, $\dagger$ 1076 different from $1.2^{\circ} \mathrm{C}$ increase in internal temperature $(\mathrm{P}<0.05)$. Figure redrawn from Ganio 1077 et al. (2012), with permission. 


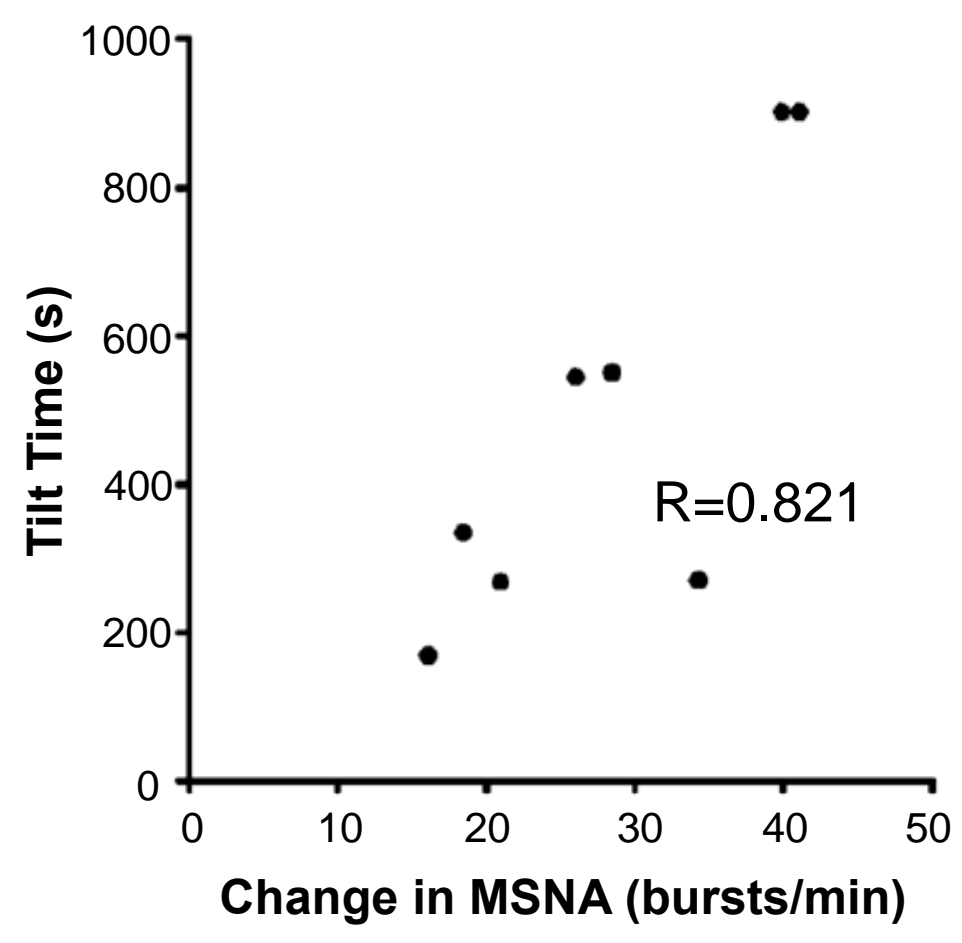

1078

1079 Figure 5: Positive correlation between the increase in muscle sympathetic nerve activity 1080 (MSNA) burst rate during orthostasis (head-up tilt) and orthostatic tolerance (tilt time, i.e., 1081 time to pre-syncope) during heat stress. These data indicate that those individuals with 1082 greatest increases in muscle sympathetic nerve activity during combined heat and 1083 orthostatic stress possess better orthostatic tolerance. Figure redrawn from Cui et al. 1084 (2011), with permission. 